\title{
OLD TECHNIQUES, NEW COMPETENCES: REBUILDING HISTORICAL INSTRUMENTS TO TEACH AND LEARN PHYSICS
}

\author{
Ana Paula B. Silva ${ }^{1}$ José Antonio F. Pinto ${ }^{1}$, Samira Arruda Vicente ${ }^{2}$, \\ \& Gerson Gonçalves ${ }^{3}$ \\ ${ }^{1}$ Department of Physics, the State University of Paraiba (Brazil) \\ ${ }^{2}$ Graduate Student, the State University of Paraiba (Brazil) \\ ${ }^{3}$ Undergraduate Student, the State University of Paraiba (Brazil)
}

\begin{abstract}
Experimental activities and the History of Science are one of the possibilities to enhance Science teaching and learning through the Historical-Investigative approach (HI). From this perspective, the HI approach focuses primarily on the use of historical case studies to explore the methodological, epistemological and conceptual aspects of scientific endeavor. Nevertheless, very little attention has been paid to the role of the required competences to the teacher who aims at applying it. In this paper, we discuss the competences that are necessary and developed by teachers and students when using the HI approach. We use a case study example which comprises the rebuilding of a 18th century instrument (Volta's pile) and its use in a Physics class based on the HI approach. Two different realities integrate the case study: a university research group environment and a high school Physics class. As part of the research group activities, an in-training teacher rebuilt that historical instrument based on the original source and designed a didactic proposal. Founded on Volta's report, he noticed some subtleties related to the 18th century knowledge on materials and procedures that were neither explicit in the report nor evident in modern piles. Furthermore, he observed that Volta's instrument was not suitable for educational use, because it required an 18th century expertise for stacking and connecting metal plates. Thus, he built two additional versions of Volta's pile for conciliating the historical report to the educational proposal. During the development of the didactic proposal, the students perceived the complexity of the scientific content on electricity. They noticed that it was impossible to rebuild Volta's pile without his report, and even when it was applied it would require to make new assumptions due to the use of new materials. To accomplish that, it was imperative the participation of the teacher showing the historical context and relating it to Volta's pile. The challenges the teacher faced to rebuild Volta's pile prepared him to deal with the students' theoretical and experimental difficulties. Moreover, they helped him foreseeing both their previous knowledge and future queries. Our research findings suggest that the success of the HI approach depends on the teacher's participation throughout the process, ranging from the reconstruction of the historical instrument to the planning of the didactic proposal. Finally, the in-training teacher can only learn and teach the methodological, epistemological and conceptual aspects of the scientific endeavor when he participates in the process.
\end{abstract}

Keywords: Historical experiments, history of science, teacher training, physics teaching.

\section{Introduction}

Contemporary literature on Science Education has emphasized the need to promote an inquiry-based learning to develop argumentative competences. The Historical-Investigative (HI) approach addresses this research program associating experimental activities and history and philosophy of Science contents (Batista; Silva, 2019; Heering; Höttecke, 2014). In the HI approach, historical case studies, which evolve experiments or instruments, are used as part of an inquiry-based lesson plan to explore the methodological, epistemological and conceptual aspects of scientific endeavor.

Some proposals based on the HI approach foresee that the rebuilding of an experiment or instrument during the classroom could lead students to explore many of their abilities and competences (Heering; Wittje, 2011; Cavicchi; 2008; Heering, 2000). However, very little attention has been paid to the role of the teacher's required competences at applying it. Among the authors who address this issue, we refer to Batista and Silva (2019) and Höttecke and Silva (2011), who argue that teachers' professional preparation is one of the biggest challenges to the effectiveness of the HI approach in a classroom. Some 
of the competences to be developed to their effectiveness are related to the deep knowledge on the historical case study and to the capacity of dealing with students' questions. In particular, teachers should be open to different possibilities of experiments and students' results, stimulating them to think about the phenomena, rather than only on the results (Pinto; Silva; Pinto, 2018; Silva; Pinto; Ferreira, 2018).

In this work, we present an empirical case study that analyses the obtained competences of an in-training teacher during the process of rebuilding and planning an inquiry-based lesson plan based on the HI approach. During the process of rebuilding an instrument to use in his classrooms, the in-training teacher presented many considerations about the historical knowledge and on how students could understand and reproduce it. All the considerations were taken to a research group, allowing it - and the teacher - to follow and observe the required competences to the lesson plan effectiveness.

\section{The historical case study: Alessandro Volta's pile}

At the end of the $18^{\text {th }}$ century, many natural philosophers, astonished with the new specimens, like the electrical fish (called torpedo), searched for a relation among animal electrical phenomena, shocks and sparks. Electricity produced by the electrical machine caused shocks and sparks; animal electricity also caused shocks. Would be both electricity from the same nature? Could animal be an electrical machine? These questions, together with the Enlightenment atmosphere, promoted an exciting research environment on electricity around Europe (PancaldI, 2003, p. 178; Martins, 2001; Martins, 1999; Mertens, 1998; Kipnis, 1987).

In 1791, Luigi Galvani (1737-1798), from the University of Bologna, published his experiments to understand frog muscle contractions. From his experiments, he presumed that animals had an intrinsic electricity (Martins, 1999). Alessandro Volta (1745-1827), from the University of Pavia, who had known about Galvani's experiments, reproduced them, but without attributing the electricity as produced by animal. As an alternative to understand the role of metals and fluids to produce and conduct electricity, Volta was led to the construction of the pile or battery ${ }^{1}$.

Volta describes his procedures to construct the battery (the apparatus) in a letter he wrote to Sir Joseph Banks, from the Royal Society, in June 26, 1800, which is partly reproduced below:

It [the apparatus] consists of a long series of an alternate succession of three conducting substances, either copper, tin and water; or, what is much preferable, silver, zinc, and a solution of any neutral or alkaline salt. The mode of combining these substances consists in placing horizontally, first, a plate or disk of silver (half-a-crown, for instance, ) next a plate of zinc of the same dimensions; and, lastly, a similar piece of a spongy matter, such as pasteboard or leather, fully impregnated with the saline solution. This set of three-fold layers is to be repeated thirty or forty times, forming thus what the author calls his columnar machine. It is to be observed, that the metals must always be in the same order, that is, if the silver is the lowermost in the first pair of metallic plates, it is to be so in all the successive ones, but that the effects will be the same if this order be inverted in all the pairs. As the fluid, either water or the saline solution, and not the spongy layer impregnated with it, is the substance that contributes to the effect, it follows that as soon as these layers are dry, no effect will be produced. (Volta, 1800, p. 27)

In the same letter, Volta observes that this apparatus gives small shocks and sparks, similarly to the torpedo and the Leyden ${ }^{2}$ jar. Nevertheless, even making it work, Volta did not know the nature of the electricity produced by the pile (Kipnis, 2001; Martins, 1999; Kipnis, 1987). This fact did not prevent the Volta's pile to be well known throughout Europe. Mertens (1998) argues that many other aspects boosted the Volta's pile, such as the scientific context of the Enlightenment and the influences of the politics, since his pile was presented to Napoleon Bonaparte during the invasion of Italy.

The preceding short history about the pile demonstrates how this subject addresses many aspects related to the scientific endeavor. Volta's description allows us discussing methodological and conceptual aspects; the controversy with Galvani and the scientific and political contexts includes epistemological aspects, as the temporary character of Science and the influences it receives from society. This was the reason why the historical case study about the pile was used for the didactical proposal reported in this paper.

\footnotetext{
${ }^{1}$ To a complete history of the battery and Galvanism during the 18th century, we suggest the reading of following works: Pancaldi (2003), Kipnis (2001), Martins (1999), and Kipnis (1987).

${ }^{2}$ The Leyden jar was widely known among the natural philosophers at the end of the 18th century (SILVA; HEERING, 2018).
} 


\section{Rebuilding and learning physics}

Our research group (Research Group of Science History and Teaching ${ }^{3}$ ) has employed the rebuilding of historical instruments and experiments to teaching in-training teachers about Science, History of Science and on Science. Historical experiments reconstruction has been explored by numerous Science historians and educators as the primary source for understanding conceptual, methodological and epistemological aspects of scientific practice (Fors; Principe; Sibum, 2016; Heering; Wittje, 2011). In this regard, the $18^{\text {th }}$ century experiments about electricity play an important role from an educational perspective, because they have many issues to be examined. The association of these experiments with an inquiry-based laboratory, as the HI approach presupposition, enable to tackle conceptual, methodological and epistemological aspects, thus contributing to the scientific literacy and understanding aspects of the nature of Science (Heering; Hötecke, 2014; Cavicchi, 2008; Volkmann; Abell, 2003).

Based on the HI approach and the designed-based research (Hoadley, 2003), we have created an educational investigative environment inside our research group following the steps: (1) an in-training teacher chooses a historical case study to rebuild the experiment; (2) an in-training teacher plans a didactical proposal using his own experiment and creates a new didactical experimental kit; (3) an in-training teacher goes to a classroom (usually a High School classroom) to implement his lesson plan. All these steps are previously discussed by the group, which is formed by professors, undergraduate Physics students and Master of Science graduate students. After each class using his proposal, the in-training teacher gives his feedback to the group, and new discussions and modifications take place as needs arise.

Regarding the case reported in this paper, the in-training teacher ${ }^{4}$ chose Volta's pile historical case study. Following the previous steps, he rebuilt the pile according to Volta's report ${ }^{5}$ (Volta, 1800). He interpreted that it should have an axis to fit the copper, zinc and wool plates (as shown in Figure 1), even if that was not explicit in Volta's report. He built the pile as seen in the figure below, and then he took it to his first Physics class experience. Notwithstanding, during the class experience with that model he noticed that the axis was a problem, as the wet plates oxidized it and it was hard to his students to set the pile up. Furthermore, they asked him to make the pile work. Therefore, the in-training teacher had two new problems to be solved: a practical one, related to his interpretation on the historical source; and a conceptual problem, related to the increase of electrical effect.

Figure 1. First pile built: inside the wood frame, there is a metal axis where the plates are fitted. Source: the authors.
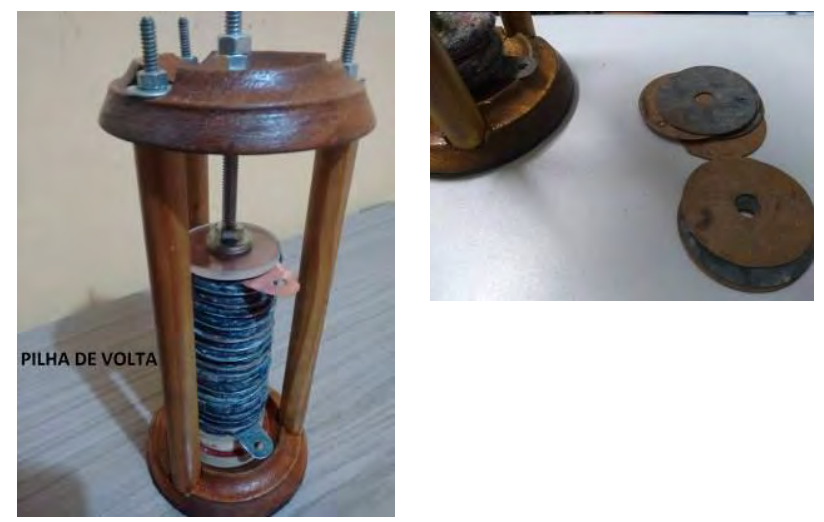

As part of the electrical phenomena investigation evolved through the pile, the in-training teacher made new tests and concluded that a higher electric current could be produced if the plates had a larger surface. Moreover, he returned his attention to Volta's report and, after a more careful reading, noticed that the axis was not really necessary. Then, he concluded that he only needed to keep the plates as a pile and put a metal connector up and down. Based on these new considerations, he built a second model (as can be seen in Figure 2) that could light up a LED.

Using the second model, he designed a new lesson plan and implemented it in his second Physics class. Now, students had no difficulty to stack the plates up and to make the pile work. The in-training teacher explained to his students the difference between the concepts of electric tension and electric current and the phenomena of oxidation-reduction. However, he was not satisfied, because the new model

\footnotetext{
${ }^{3}$ https://ghcenuepb.wixsite.com/ghcen

${ }^{4}$ The in-training teacher is the fourth author of this paper.

${ }^{5}$ The source we used (MAGNAGHI; ASSIS, 2008) was translated into Portuguese.
} 
was far from the historical images from the $18^{\text {th }}$ century pile. Thus, he concluded that the historical apparatus should both use more plates (and generate a higher electric current) and be more delicate than the second model. These new conclusions took him to build the third model (as shown in Figure 3). By using more plates but without the central axis, he could get higher electric current and, at the same time, make the pile easier to be understood and reproduced by the students. Then, he used the third model in a third implementation of a better designed Physics class lesson plan, attracting the students' attention and motivation to the investigative activity and comprehension of the Physics concepts.

During the process of building and rebuilding the pile, the in-training teacher tested the models with the research group members and in the classroom activities. The research group members and students' queries helped him to rethink the instrument and the electric phenomena, almost simulating the $18^{\text {th }}$ century scientific academy. As in Volta's case study, the in-training teacher was able to understand that the electric phenomena were due to the metal properties, and that the wet wool worked as a medium. Therefore, improving implied the need to increase the plates either regarding to their number or surface. At the same time, it was necessary to keep the pile stable with all the plates in contact (which is the function of the wood wall and the screw thread).

Figure 2. Second pile built: the plates are larger than in the first pile. A wood wall and a screw thread help to keep the plates aligned. Source: the authors.

Figure 3. Third pile built: the apparatus is more similar to historical images, and it is able to light up a LED. A screw thread and a thin wood wall keep the plates as a pile. Source: the authors.
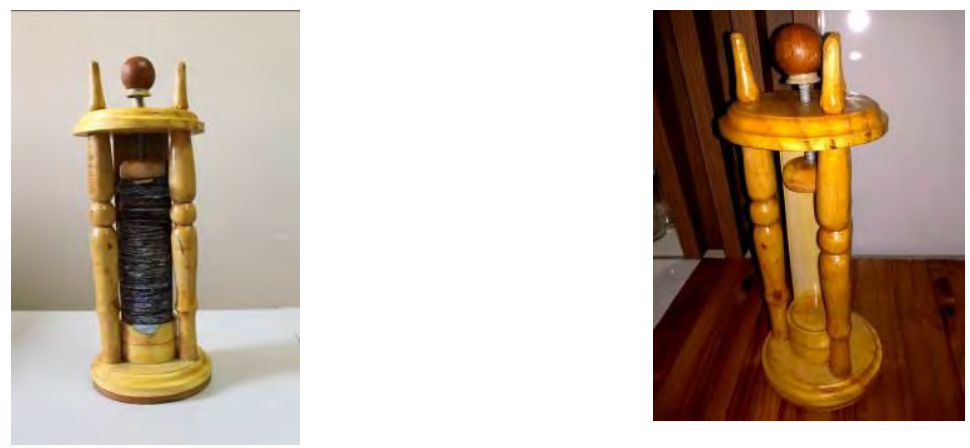

\section{Conclusions}

The investigation of historical case studies to explore the methodological, epistemological and conceptual aspects of scientific endeavor helped the in-training teacher to plan the first version of his didactical proposal. When he started to implement it, the group members and students' difficulties and queries led him to rethink the historical apparatus, as it happened in the Galvani-Volta controversy.

The whole process, which took place in three experiences in Physics classes, was over a year long, ranging from the first model to the final version of the didactical proposal. During that period, the participation in the research group helped the in-training teacher to improve his abilities and acquire new competences related to the investigation. As part of the process, he learned to question the historical sources and to understand that the scientific knowledge is more complex than simply reproducing ready results. As he investigated the conceptual phenomena involved in the pile to answer the students' queries, he became more self-confident to teach and to deal with new challenges in the classroom. 
In brief, based on our findings, we would like to highlight that, to the effectiveness of the HI approach, it is essential the in-training teacher's participation throughout the process, ranging from the reconstruction of the historical instrument to the planning of the didactic proposal, as we strongly believe that it is during this process that the teacher learns how to deal with the challenges of the HI approach and to improve his Science teaching and learning.

\section{Acknowledgements}

The authors acknowledge the financial support of the National Council of Scientific and Technological Development (no. 474924/2012-2) and the State University of Paraiba, Brazil.

\section{References}

Batista, R. F. M. \& Silva, C.C. (2019). When Things Go Wrong. Science \& Education, 1-17. Online first. https://doi.org/10.1007/s11191-019-00071-z.

Cavicchi, E. M. (2008). Historical experiments in students' hands: unfragmenting Science through action and history. Science \& Education, 17(7), 717-749.

Fors, H.; Principe, L. M. Principe \& Sibum, H. O. (2016) From the Library to the Laboratory and Back Again: Experiment as a Tool for Historians of Science, Ambix, 63(2), 85-97.

Heering, P. (2000). Getting shocks: Teaching secondary school physics through history. Science \& Education, 9 (4), 363-373.

Heering, P., \& Höttecke, D. (2014). Historical-investigative approaches in Science teaching. In: M. R. Matthews (Ed.), International handbook of research in history, philosophy and science teaching (pp. 1473-1502). Netherlands: Dordrecht: Springer.

Heering, P., \& Wittje, R. (2011). Learning by doing. Experiments and instruments in the History of Science Teaching. Franz Steiner Verlag. (elibrary). Retrieved from https://elibrary.steinerverlag.de/book/99.105010/9783515100151.

Hoadley, C. Design-Based Research Collective. (2003). Design-based research: an emerging paradigm for educational inquiry. Educational Researcher, 32(1), 5-8. https://doi.org/10.3102/0013189X032001005.

Höttecke, D., \& Silva, C. C. (2011). Why implementing history and philosophy in school science education is a challenge: an analysis of obstacles. Science \& Education, 20(3), 293-316.

Kipnis, N. (1987) Luigi Galvani and the debate on animal electricity, 1791-1800. Annals of Science, 44(2), 107-142.

Kipnis, N. (2001). Scientific controversies in teaching Science: the case of Volta. Science \& Education, $10(1-2), 33-49$.

Magnaghi, C. P., \& Assis, A. K. T. (2008). Sobre a eletricidade excitada pelo simples contato entre substâncias condutoras de tipos diferentes uma tradução comentada do artigo de volta de 1800 descrevendo sua invenção da pilha elétrica. Caderno Brasileiro de Ensino de Física, 25(1), 118-140.

Martins, R. A. (1999). Alessandro Volta e a invenção da pilha: dificuldades no estabelecimento da identidade entre o galvanismo e a eletricidade. Acta Scientiarum, 21(4), 823-835.

Martins, R. A. (2001). Romagnosi and Volta's pile: Early difficulties in the interpretation of Voltaic electricity. Nuova Voltania: Studies on Volta and his Times, 3, 81-102.

Mertens, J. (1998). Shocks and sparks: the voltaic pile as a demonstration device. Isis, 89(2), 300-311.

Pancaldi, G. (2003). Volta. Science and Culture in the Age of Enlightenment. Princeton: Princeton University Press.

Pinto, I. K. L. S; Silva, A. B., \&; Pinto, J. A. F. (2018) Entre o planejamento e a execução: desafios de uma abordagem histórica para ensinar eletrostática. Experiências em Ensino de Ciências, 13(3), 192-211.

Silva, A. P. B.; Pinto, J. A. F., \& Ferreira, E. J. B. (2018) Design and implementation of a lesson plan for high school students: a case study with Oersted's experiment. (pp. 327-339). In: M. E. B. Prestes, M. E. B. \& C. C. Silva (Eds.). Teaching Science with Context. Netherlands: Springer.

Silva, C. C., \& Heering, P. (2018). Re-examining the early history of the Leiden jar: Stabilization and variation in transforming a phenomenon into a fact. History of Science, 56(3), 314-342.

Volkmann, M. J., \& Abell, S. K. (2003). Rethinking laboratories: tools for converting cookbook labs into inquiry. The Science Teacher, 70(6), 38-41.

Volta, A. (1800) On the electricity excited by the mere contact of conducting substances of different kinds. Abstracts of the papers printed in the Philosophical Transactions of the Royal Society of London, 1, 1800-1814, 27-29. 